\title{
Origin(s) of Anomalous Substrate Conduction in MOVPE-Grown GaN HEMTs on Highly Resistive Silicon
}

Saptarsi Ghosh,* Alexander Hinz, Simon M. Fairclough, Bogdan F. Spiridon, Abdalla Eblabla, Michael A. Casbon, Menno J. Kappers, Khaled Elgaid, Saiful Alam, Rachel A. Oliver, and David J. Wallis

Cite This: ACS Appl. Electron. Mater. 2021, 3, 813-824

Read Online

ACCESS |

Llll Metrics \& More

Article Recommendations

Supporting Information

ABSTRACT: The performance of transistors designed specifically for high-frequency applications is critically reliant upon the semiinsulating electrical properties of the substrate. The suspected formation of a conductive path for radio frequency (RF) signals in the highly resistive (HR) silicon substrate itself has been long held responsible for the suboptimal efficiency of as-grown GaN high electron mobility transistors (HEMTs) at higher operating frequencies. Here, we reveal that not one but two discrete channels distinguishable by their carrier type, spatial extent, and origin within the metal-organic vapor phase epitaxy (MOVPE) growth process participate in such parasitic substrate conduction. An $\mathrm{n}$ -

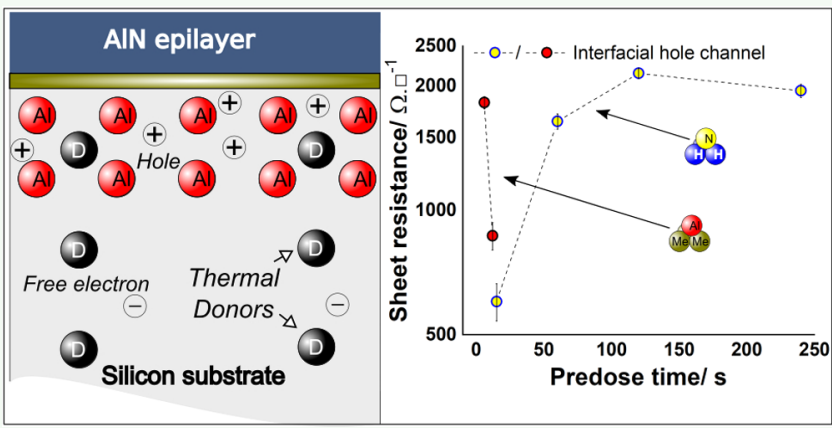
type layer that forms first is uniformly distributed in the substrate,

and it has a purely thermal origin. Alongside this, a p-type layer is localized on the substrate side of the AlN/Si interface and is induced by diffusion of group-III element of the metal-organic precursor. Fortunately, maintaining the sheet resistance of this p-type layer to high values $(\sim 2000 \Omega / \square)$ seems feasible with particular durations of either organometallic precursor or ammonia gas predose of the $\mathrm{Si}$ surface, i.e., the intentional introduction of one chemical precursor just before nucleation. It is proposed that the mechanism behind the control actually relies on the formation of disordered AlSiN between the crystalline AlN nucleation layer and the crystalline silicon substrate.

KEYWORDS: GaN-on-Si, GaN HEMTs, AlN nucleation, III-nitride MOVPE, parasitic conduction, RF loss

\section{INTRODUCTION}

Access to a plethora of physical properties within the same semiconductor family and simultaneous opportunity to design application-specific heterostructures has generated tremendous interest in III-nitride ( $\mathrm{Al}, \mathrm{Ga}$, and In being the group-III elements)-based electronics in the past two decades. Owing to the relentless device engineering ${ }^{1-5}$ and the vital combination of wide band gap, high electron saturation velocity, and ultralow channel resistance, $\mathrm{AlGaN} / \mathrm{GaN}$ and InAlN/GaN high electron mobility transistors (HEMTs) are now highly promising candidates for microwave signal amplification. Unfortunately, the lack of scalable and cost-effective III-nitride substrates has constrained the realization of such functional layers to non-native platforms such as $\mathrm{SiC}$, sapphire, or silicon. Unparalleled large-area availability, low-cost, and fabrication maturity make silicon the most commercially attractive among the three. However, along with lattice mismatch, epitaxy of IIInitrides on silicon brings the additional challenges of melt-back etching ${ }^{6,7}$ and stress management. ${ }^{8,9}$ This has resulted in AlN nucleation ${ }^{10,11}$ layers and graded AlGaN buffers ${ }^{12,13}$ becoming integral components of III-nitride heterostructures grown on silicon. At times, the adverse electrical implications of these additional layers have proven to be a reason for concern, necessitating further scrutiny. In this context, though the illeffects of the AlGaN buffers in the form of leakage $e^{14,15}$ and trapping ${ }^{16,17}$ are now relatively well understood and controlled, the suspected association of the AlN nucleation layer with the formation of a conductive channel at the AlN/Si interface is still under debate. Crucially, apart from thermal conductivity, the power loss due to this channel has been alleged to be the remaining bottleneck ${ }^{18,19}$ for the high-frequency performance (i.e., maximum power gain frequency and power output) of record-breaking GaN-on-Si HEMTs ${ }^{20,21}$ still lagging behind the devices grown on $\mathrm{SiC} .^{22,23}$

With several mutually exclusive theories being discussed in the scientific community, both the origin and the identity of this unintentional substrate conductivity in metal-organic vapor phase epitaxy (MOVPE)-grown heterostructures have always been controversial. For instance, an inversion layer of

Received: November 2, 2020

Accepted: January 7, 2021

Published: January 25, 2021

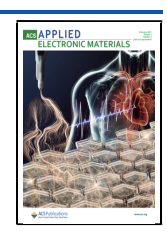


electrons ${ }^{24,25}$ arising from an abrupt AlN/Si interface and oxynitride acceptor traps ${ }^{26}$ due to a nonideal AlN/Si interface have both been independently proposed to explain the presence of mobile carriers. Separately, group-III elemental diffusion into the silicon substrate (and acting as acceptors) has been attributed as the causal mechanism by several authors $^{27-33}$ alongside suggestions of diffusion partly arising from residual species in the reactor. ${ }^{27,29,32}$ Arguments negating the role of the substrate also exist, with the AlN nucleation layer itself held accountable for being conductive. ${ }^{34}$ Irrespective of the origin, the presence of a capacitively coupled buried channel greatly undermines the potential of $\mathrm{GaN}$ HEMTs by inducing power loss not only for the transistors but also for the passive components and the connecting transmission lines of the integrated circuits (ICs); for example, investigations on structures grown by molecular beam epitaxy (MBE) process have identified that controlling the epi/ substrate interface is essential to minimize parasitic conduction and radio frequency (RF) loss. ${ }^{35,36}$ Given the superior growth rates and wafer throughput but also the different thermodynamics and reaction kinetics of the MOVPE technique, understanding and controlling the physical origin of the parasitic conduction path in MOVPE-grown structures have become important to the demonstration and large-scale production of high-performance GaN-on-Si RF electronics. Using this motivation, the present investigation aims to establish an unambiguous correlation between the observed buried conductivity and the prenucleation stages of the IIInitride-on-Si epitaxy. To achieve this, we investigate the origins of conductivity in AlN-on-Si layers, which represent the initiation of the standard HEMT growth process. After MOVPE deposition, we have implemented eddy currentbased resistance evaluation, Hall-effect measurement, and scanning capacitance microscopy (SCM) to extract the magnitude, spatial distribution, and carrier type of the conductive channels. In parallel, we have analyzed the surfaces and the interfaces through atomic force microscopy (AFM), secondary ion mass spectroscopy (SIMS), and cross-sectional scanning transmission electron microscopy (STEM) with electron energy loss spectroscopy (EELS) to provide a unified insight into channel formation.

\section{RESULTS AND DISCUSSION}

II.I. Epitaxy of Aluminum Nitride on Silicon. Similar to RF Si-complementary metal-oxide-semiconductor (CMOS) devices, for high-frequency $\mathrm{GaN}$-on-Si applications, it is customary to grow upon highly resistive (HR) silicon wafers so that the power loss due to substrate conductivity is at par with semi-insulating GaAs. ${ }^{37}$ Accordingly, Czochralski (CZ)type HR-Si(111) substrates (specified resistivity $\geq 3 \mathrm{k} \Omega \mathrm{cm}$ ) were chosen for the study. Note that float-zone (FZ) HR wafers were intentionally avoided given their higher cost and propensity to plastic deformation (such as slip) at MOVPE process temperatures. $^{38,39}$ Prior to growth, noncontact RF eddy current induction-based evaluation ${ }^{40}$ confirmed that sheet resistances $\left(R_{\mathrm{SH}}\right)$ of all of the eight wafers were higher than the limit of the measurement system $(\sim 10 \mathrm{k} \Omega / \square)$. On six of these, a nominally $250 \mathrm{~nm}$ thick AlN nucleation layer was grown by MOVPE under conditions typical of our standard HEMT structures. ${ }^{15,41,42}$ In detail, this AlN layer growth is divided into four steps, which are successively performed in the reactor. Step-I (oxide desorption): in situ removal of the native oxide on silicon by high-temperature $\left(1080{ }^{\circ} \mathrm{C}\right)$ annealing in a
$\mathrm{H}_{2}$ ambient to generate a step-terraced surface; step-II (precursor predose): short injection of either $\mathrm{NH}_{3}$ or trimethylaluminum (TMAl) at $990{ }^{\circ} \mathrm{C}$; step-III (low-temperature nucleation): growth of $\approx 50 \mathrm{~nm}$ AlN with simultaneous $\mathrm{NH}_{3}$ and TMAl flow at $990^{\circ} \mathrm{C}$; and step-IV (high-temperature growth): growth of the remaining AlN layer with simultaneous $\mathrm{NH}_{3}$ and TMAl flow at $1090^{\circ} \mathrm{C}$.

For step-II, both $\mathrm{NH}_{3}$ and TMAl predoses may be discovered in the literature. ${ }^{29,43-47}$ In this study, while keeping all of the other steps identical, the predose step was varied with four durations $(15,60,120$, and $240 \mathrm{~s})$ of $\mathrm{NH}_{3}$ flux at 40 $\mu \mathrm{mol} / \mathrm{s}$ and two durations (6 and $12 \mathrm{~s}$ ) of TMAl flux at 0.2 $\mu \mathrm{mol} / \mathrm{s}$ to realize six uncracked AlN-on-Si epistructures. Also, complete HEMT stacks were grown on comparable AlN nucleation layers in separate process runs, comprising additional deposition of a linearly graded AlGaN buffer, GaN buffer, GaN channel, AlGaN barrier, and GaN cap of the standard structure. All of these crack-free and low-bowed ( 50 $\mu \mathrm{m}$, convex) heterostructures showed a characteristic twodimensional (2D) electron gas (2DEG) density of $\sim 8 \times 10^{12}$ $\mathrm{cm}^{-2}$, which confirmed their technological relevance. Also, as summarized in Table 1, a reference wafer was kept pristine for

Table 1. Summary of the Eight Wafers Investigated, including the Temperature and Duration of the Procedural Steps

\begin{tabular}{|c|c|c|c|}
\hline structure & $\mathrm{H}_{2}$ anneal & precursor predose & $250 \mathrm{~nm}$ AlN growth \\
\hline $\begin{array}{l}\text { reference substrate } \\
\text { (RS-1) }\end{array}$ & - & - & - \\
\hline $\begin{array}{l}\text { reference substrate } \\
\quad(\text { RS-2) }\end{array}$ & $\begin{array}{r}1080^{\circ} \mathrm{C} \\
30 \mathrm{~min}\end{array}$ & - & - \\
\hline $\begin{array}{l}\text { AlN-on-Si templates } \\
\left(\mathrm{NH}_{3} \text { predosed }\right)\end{array}$ & $\begin{array}{r}1080{ }^{\circ} \mathrm{C}, \\
30 \mathrm{~min}\end{array}$ & $\begin{array}{r}990^{\circ} \mathrm{C} \\
(15 / 60 / 120 / 240) \mathrm{s}\end{array}$ & $\begin{array}{l}990^{\circ} \mathrm{C}, 11 \mathrm{~min}+ \\
1090^{\circ} \mathrm{C}, 80 \mathrm{~min}\end{array}$ \\
\hline $\begin{array}{l}\text { AlN-on-Si templates } \\
\text { (TMAl predosed) }\end{array}$ & $\begin{array}{r}1080^{\circ} \mathrm{C}, \\
30 \mathrm{~min}\end{array}$ & $990{ }^{\circ} \mathrm{C},(6 / 12) \mathrm{s}$ & $\begin{array}{l}990^{\circ} \mathrm{C}, 11 \mathrm{~min}+ \\
1090^{\circ} \mathrm{C}, 80 \mathrm{~min}\end{array}$ \\
\hline
\end{tabular}

comparison (RS-1), i.e., not subjected to any of the steps, whereas for another wafer (RS-2), the growth process was terminated directly after step-I, i.e., before injecting any precursor into the reactor.

II.II. Electrical, Structural, and Chemical Analysis. After growth, the $R_{\mathrm{SH}}$ of all of the AlN-on-Si wafers were measured again by the eddy current-based method, and the resulting values are plotted in Figure 1. The figure shows two data sets at each predose of $\mathrm{NH}_{3}$ (main graph) or TMAl (inset) representing the $R_{\mathrm{SH}}$ values for the as-grown structures and after removal, by grinding, of $200 \mu \mathrm{m}$ of material from the backside of the $\mathrm{Si}$ substrate. Among the wafers with full thickness, the average $R_{\mathrm{SH}}$ of RS-2 was reduced to $596 \Omega / \square$ by just the processes in step-I of the growth (up to and including the $\mathrm{H}_{2}$ anneal), a change of almost 2 orders of magnitude. With as-grown AlN, the $R_{\mathrm{SH}}$ were even lower, but the exact value was predose-dependent; for example, increasing the duration of $\mathrm{NH}_{3}$ predose resulted in a systematic increase of $R_{\mathrm{SH}}$ from 279 to $441 \Omega / \square$, whereas increasing the TMAl duration caused a small decrease from 427 to $409 \Omega / \square$. Thinning of the substrate was performed to remove any effects of group-III diffusion into the backside of the $\mathrm{Si}$ wafer, which could result from residual contamination of the susceptor (on which the substrate is placed), and as the eddy current-based method measures the full thickness of the sample, it would contribute to the measured conductance. As shown in Figure 1, after thinning, the $R_{\mathrm{SH}}$ of thinned RS-2 was $1058 \Omega / \square$, 


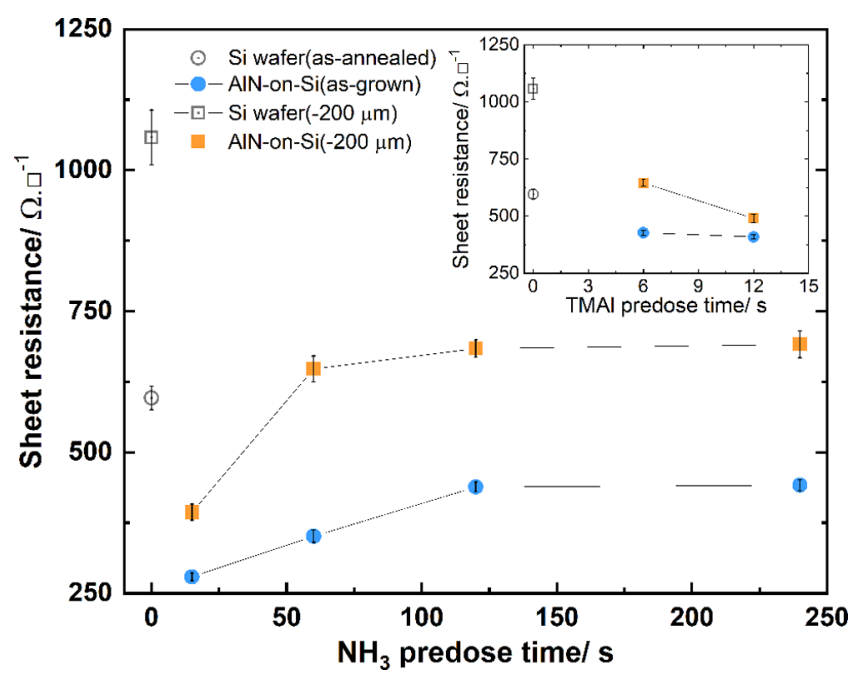

Figure 1. Dependence of AlN-on-Si average sheet resistance on the $\mathrm{NH}_{3}$ predose duration. The inset shows the dependence for the TMAl predose durations. The two data at each predose represent the values for as-grown structures (symbol: circle) and after $200 \mu \mathrm{m}$ backside grinding (symbol: square). For reference, the measured values of the annealed substrate (RS-2) are also shown in the plots.

whereas $R_{\mathrm{SH}}$ for the thinned templates varied from 393 to 691 $\Omega / \square$ for the $\mathrm{NH}_{3}$ predose and from 645 to $491 \Omega / \square$ for the TMAl predose, retaining the same qualitative dependence on predose, although at higher values. The presence of conductivity in all of the wafers even after backside grinding indicates the presence of sources of carriers in addition to/ distinct from backside contamination. However, the fact that measurements of RS-1 after thinning yielded a characteristic $\geq 10 \mathrm{k} \Omega / \square$ value (not shown) allows any influence of the grinding process itself on conductivity to be ruled out.

To understand whether any of the decrease in $R_{\mathrm{SH}}$ of RS-2 was caused by elemental diffusion into the front surface of the

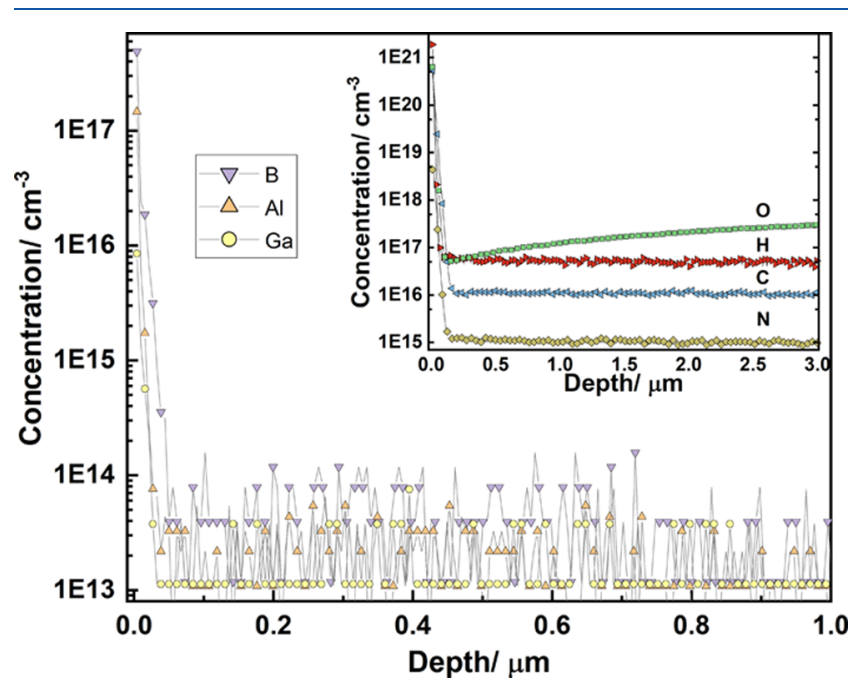

Figure 2. SIMS evaluated atomic concentration of different group-III species in the silicon substrate that was annealed under $\mathrm{H}_{2}$ ambient (RS-2). The corresponding profiles of other probable contaminants are shown in the inset. Except oxygen, none of these exhibited any meaningful variation within the probed depths and were at their respective detection limit. In both the graphs, the origin of the $x$-axis denotes the top silicon surface. wafer during the annealing step, which would then similarly affect the AlN-on-Si templates, the near-surface region of the thinned RS-2 was scrutinized by SIMS.

As shown in Figure 2, none of the group-III species used in the reactor had any variation suggestive of an in-diffusion process (the profiles at $\leq 50 \mathrm{~nm}$ from the surface are not "real" features) and were below the SIMS detection limit. This not only attests to the success of the strictly followed reactor purge routines but also confirms that the conductivity measured in RS-2 after annealing does not arise from residual ${ }^{27,29} \mathrm{Al}$ or $\mathrm{Ga}$. Importantly, as shown in the inset, it was also confirmed that none of the probable contaminants such as $\mathrm{C}, \mathrm{N}$, or $\mathrm{H}$ had diffused into the substrate either. It is worth mentioning that the $\mathrm{N}$ depth profile with a sharp increase near the surface was similar to that observed by Chandrasekar ${ }^{26}$ et al., who linked such a variation with the conductivity of AlN-on-Si through an alleged formation of a $\mathrm{Si}-\mathrm{O}-\mathrm{N}$ complex. We argue that such rapid decays within $\sim 100 \mathrm{~nm}$ from the sample surface (or interface) are more likely to be an artificial feature for adventitious surface species (or resputtered matrix effect). Among all of the inspected elements, only $\mathrm{O}$ had a depthdependent variation indicative of out-diffusion marked by an increase up to $3 \mu \mathrm{m}$ depth, beyond which this interstitial species $^{48}$ is expected to level off at the bulk concentration of mid-10 ${ }^{17} \mathrm{~cm}^{-3}$ for Czochralski (CZ)-grown silicon.

To clarify the carrier type and densities giving rise to the measured conductivity, scribed samples from all wafers were then subjected to Hall-effect measurements. While attempts were made to contact the samples from both the AlN side and rear of the wafers, the measured $I-V$ characteristics of these samples indicated that only contacts on the backside of the silicon were ohmic. The Hall coefficients $\left(R_{\mathrm{H}}\right)$ were confirmed to be negative for all of the specimens indicating that the dominant carriers were electrons. The calculated areal densities averaged from three to six samples of each wafer are listed in Table 2, and within the small test population, no significant variation was observed, with average values ranging from $4.2 \times$ $10^{12}$ to $6.3 \times 10^{12} \mathrm{~cm}^{-2}$, which is similar to the $5.2 \times 10^{12} \mathrm{~cm}^{-2}$ observed for RS-2. Since these carriers could be either evenly distributed through the thickness of the $\mathrm{Si}$ or form a localized layer, additional depth-dependent Hall-effect measurements were carried out in an attempt to identify any evidence for the proposed inversion layer localized at the AlN/Si interface that would host a similar sheet carrier density. ${ }^{25}$ For these measurements, separate samples were scribed and then polished from either the backside or the topside to reduce their thickness. Note that thinning from the topside involved complete removal of the AlN and its interface with silicon. As detailed in Table 2, the thinned samples showed a decrease in areal carrier density that was clearly proportional to the decrease in thickness. These experiments along with the similar value for carrier density in RS-2 and all of the templates proved that electrons causing this unintended conductivity were actually distributed throughout the thickness of the bulk silicon with an approximate volume concentration of mid- $10^{13}$ $\mathrm{cm}^{-3}$. Notably, even after thinning, no specimens from RS-1 could be probed, reconfirming that the modified substrate conductivity was indeed annealing or growth process-induced.

Nonetheless, the above-mentioned electrical measurements do not exclude the presence of an additional interfacial channel and in fact the variation in $R_{\mathrm{SH}}$ with predose duration shown in Figure 1 strengthens this notion. To inspect the details of any conductivity arising adjacent to the $\mathrm{AlN} / \mathrm{Si}$ interface, cross- 
Table 2. Hall-Effect Measurement Results on Samples from the Annealed Si Wafer and the AlN-on-Si Structures with Different Predoses $^{a}$

\begin{tabular}{|c|c|c|c|c|c|c|c|}
\hline & only $\mathrm{H}_{2}$ annealed (RS-2) & $\mathrm{NH}_{3} / 15 \mathrm{~s}$ & $\mathrm{NH}_{3} / 60 \mathrm{~s}$ & $\mathrm{NH}_{3} / 120 \mathrm{~s}$ & $\mathrm{NH}_{3} / 240 \mathrm{~s}$ & TMAl/6 s & TMAl/12 s \\
\hline series-A: $\mathrm{e}^{-}$density $\left(10^{12} \mathrm{~cm}^{-2}\right)$ & $5.2 \pm 0.8$ & $5.7 \pm 0.3$ & $4.4 \pm 0.3$ & $5.1 \pm 0.5$ & $4.2 \pm 0.1$ & $6.3 \pm 0.5$ & $5.6 \pm 0.9$ \\
\hline series-B: $\mathrm{e}^{-}$density $\left(10^{12} \mathrm{~cm}^{-2}\right)$ & $4.9(750 / \mathrm{T})$ & $2.9(450 / \mathrm{B})$ & & $2.8(460 / \mathrm{B})$ & $2.4(450 / \mathrm{T})$ & & \\
\hline
\end{tabular}

${ }^{a}$ Series-A: mean and uncertainty values for several samples from each wafer with an $800 \mu \mathrm{m}$ substrate thickness. Series-B: as-measured value for further thinned samples from particular wafers. For series-B, the final sample thickness (in $\mu \mathrm{m}$ ) and the side from which the material was removed are mentioned inside the brackets as T: AlN topside and B: silicon backside.

sectional scanning capacitance microscopy (SCM) was carried out. This electrical variant of contact-mode atomic force microscopy (AFM) utilizes the bias-dependent differential capacitance of the tip-to-semiconductor junction and simultaneously acquires topography and a local charge-carrier data map. ${ }^{15,49,50}$ The measurements were carried out on cleaved cross sections. First, the upper edge of the cross section above the AlN layer was identified from an abrupt and characteristic increase of the measured deflection error. Then, using the thickness of the AlN as a guide, approximately $10 \mu \mathrm{m}$ into the silicon substrate was scanned for samples from all of the templates.

Figure 3 shows the representative topography and $\mathrm{d} C / \mathrm{d} V$ phase $\left(\Delta \phi=\phi-\phi_{\mathrm{L}}\right.$, where $\phi_{\mathrm{L}}$ is the lock-in phase) map of a $1.5 \mu \mathrm{m} \times 10 \mu \mathrm{m}$ (width $\times$ depth) subsurface region from the structure with a $15 \mathrm{~s} \mathrm{NH}_{3}$ predose. In SCM, phases of the conducting regions can be used to assign the carrier type. The bimodal distribution in the phase maps of Figure 3 reveals that the phase responses for the two conducting regions are $180^{\circ}$ out of phase indicating opposite carrier polarity. Referencing the buried conducting region $\left(\Delta \phi \sim-90^{\circ}\right)$ in the maps as the newly formed bulk n-type layer in silicon, the channel $(\Delta \phi \sim$ $+90^{\circ}$ ) present at the AlN/Si interface is clearly p-type. This presence of both types of carriers was observed in the crosssectional scan of every AlN-on-Si structure. Notably, on some samples, the buried layer did not appear at zero DC bias but superimposing a DC bias during the scans revealed that this layer was indeed present (see the Supporting Information). As for the p-type layer, though some variation in the depth of this region was observed within samples, its presence was clearly identifiable in all of the samples at zero DC bias irrespective of the predose type and duration. Without a calibration staircase $^{49}$ within the AlN-on-Si structure, quantitative calculations of hole concentrations are not possible from the SCM data itself. Nonetheless, the presence of this additional layer explains the cause of further decreased sheet resistance in the epistructures compared to that of the annealed substrate.

SCM phase data yields no fixed value when scanning insulating regions, or regions of extremely low carrier concentration, due to the lack of carriers to modulate. Such insulating regions appear as noise in typical SCM images. Between the p-type and the n-type regions, there is such a noisy band in the phase maps with $\phi \sim \phi_{\mathrm{L}}$. This likely arises from an equilibrium depletion region between the conducting layers. Previously, Matsumoto ${ }^{29}$ et al. observed in scanning spreading resistance microscopy (SSRM) a gradual decrease followed by an abrupt drop of carrier concentration below the AlN/Si interface in GaN/AlN/Si structures. The authors had credited the latter effect to passivation of carriers by diffused $\mathrm{H}_{2}$. The lack of carrier-type information from the SSRM data and the limited scan size $(\sim 3 \mu \mathrm{m})$ of their study precludes a direct comparison with our data. However, the results are
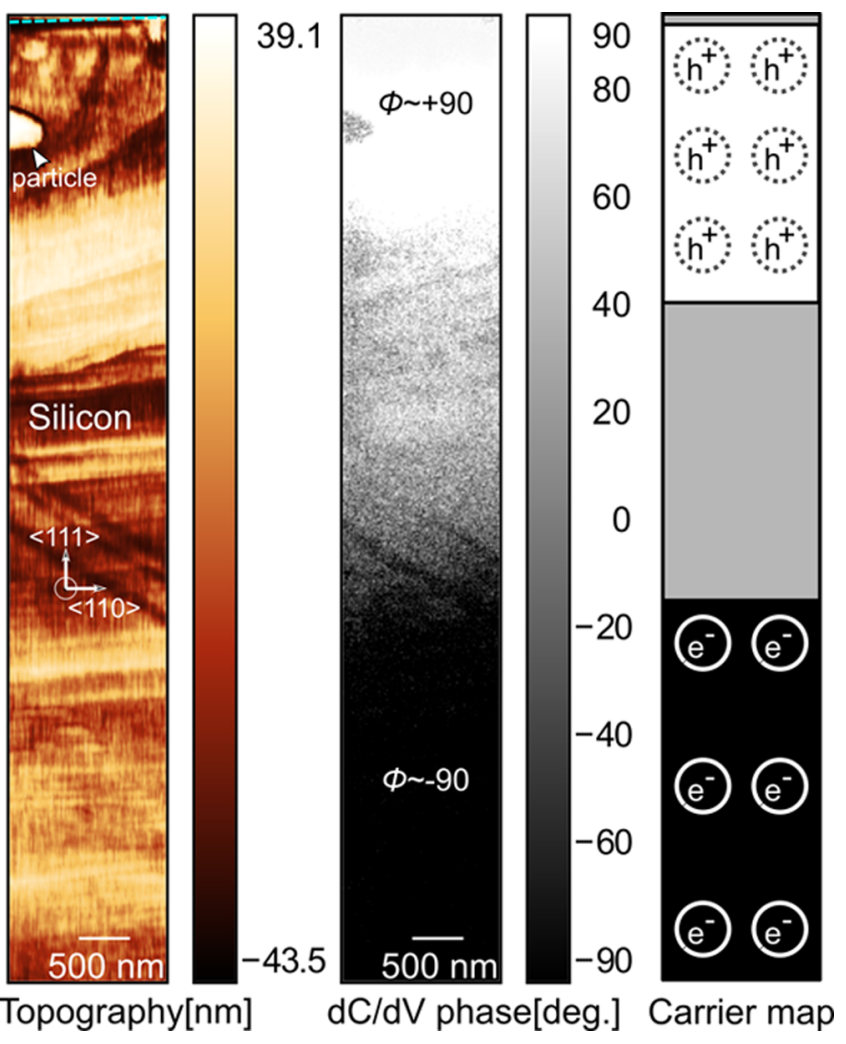

Figure 3. Three-dimensional (3D) topography and $2 \mathrm{D} d C / \mathrm{d} V$ phase map from a cross-sectional specimen of the $15 \mathrm{~s} \mathrm{NH}_{3}$ predosed AlNon-Si structure. The approximate position of the AlN/Si interface is indicated by a dashed line in the topography image. The phase map validates that carriers of the two conducting layers in silicon have opposite polarity $\left(\Delta \phi \sim+90^{\circ}\right.$ and $-90^{\circ}$, represented as white and dark regions, respectively) and they are separated by a zone lacking free carriers $\left(\Delta \phi \sim 0^{\circ}\right.$, gray region). From this phase response, the carriers can be designated as shown in the color-coded carrier map schematic. The near-surface carriers are identified as holes, whereas the buried carriers are identified as electrons along with a region lacking carriers between the two conducting layers. Note that the roughness arising from cleavage planes and morphological features of the sidewalls had minimal influence on the overall phase data.

consistent with the presence of a hole channel followed by a depletion region, similar to that observed here.

Very recently, the presence of a p-type layer followed by a depletion region that is formed with the FZ-grown n-type substrate has been evidenced by $\mathrm{Bah}^{32}$ et al. through coupled SCM and SSRM experiments. For AlN grown with a fixed $\mathrm{NH}_{3}$ predose, those authors had observed a proportional relationship between the AlN growth temperature and the width of the p-type layer. Though such a systematic variation of the p-type layer width could not be established for the present structures, its existence localized at the $\mathrm{AlN} / \mathrm{Si}$ interface indeed explains the source of decreased sheet resistance in the epistructures 
compared to that of the annealed silicon substrate, and our data shows that the conductivity of this channel can be varied with the predose type and duration. In view of the Hall-effect results, assuming the sheet resistance of the bulk n-type regions to be invariant for all of the structures and equal in magnitude with RS-2, the specific $R_{\mathrm{SH}}$ of the p-type layer were extracted for each template. For the samples with an $\mathrm{NH}_{3}$ predose, the plotted values in Figure 4 first show a rapid increase from 602

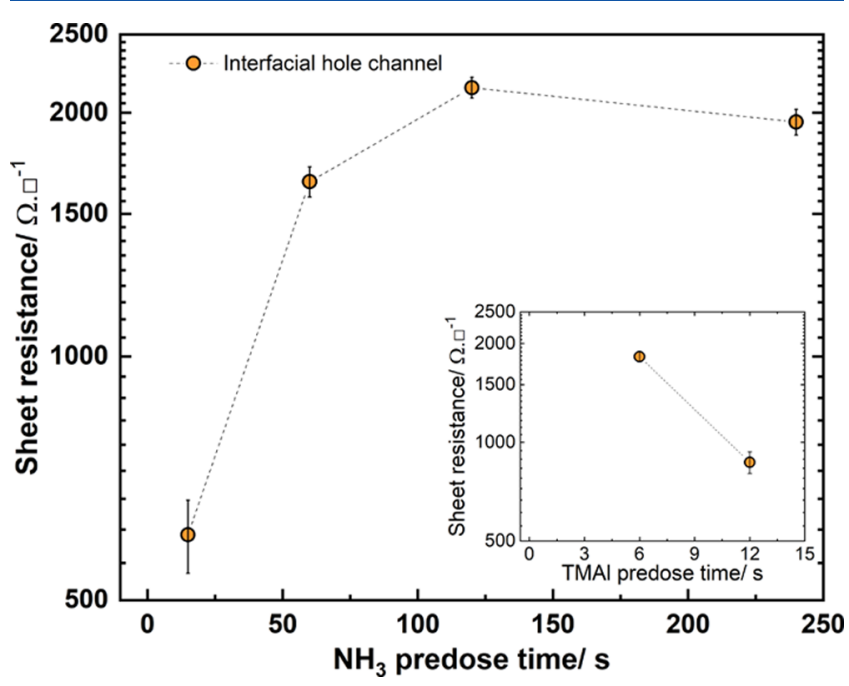

Figure 4. Calculated average sheet resistances of the p-type layer for increasing durations of the $\mathrm{NH}_{3}$ predose. These show an initial increase followed by saturation. Corresponding values for the TMAl predoses in the inset reveal a fast decrease instead. All of the calculations assume that the n-type and p-type layers independently conduct in parallel.

to $1644 \Omega / \square$ with increase in the duration from 15 to $60 \mathrm{~s}$ but become approximately constant for predose times between 120 and $240 \mathrm{~s}$ at around $2000 \Omega / \square$. In contrast, a fast decrease from 1824 to $869 \Omega / \square$ can be seen for increasing TMAl predose from 6 to $12 \mathrm{~s}$. As $R_{\mathrm{SH}}=\rho_{\text {channel }} / t$, where $\rho$ and $t$ denote the channel resistivity and thickness, considering $t$ of the SCM-resolved p-type layer to be $\sim 3 \mu \mathrm{m}$ and approximating a uniform distribution, these values reveal an associated resistivity of $\sim 0.2-0.6 \Omega \mathrm{cm}$, suggesting $10^{16}-10^{17} \mathrm{~cm}^{-3}$ acceptors on average for the whole layers. Notably, such magnitudes of unintentional doping agree well with both the estimated volume concentration of holes ${ }^{32}$ in the p-type layer and the ranges of the reported ${ }^{26,27,29}$ SIMS depth profiles for group-III species. Also, in conjunction with the Hall effectmeasured n-type carrier concentrations (i.e., mid- $10^{13} \mathrm{~cm}^{-3}$ ), these values of $\mathrm{p}$-type carriers should result in a $\mathrm{p}-\mathrm{n}$ junction depletion region of $\sim 4 \mu \mathrm{m}$, quite consistent with those observed in SCM.

Importantly, it becomes obvious that for the inspected flow rates, $\mathrm{NH}_{3}$ provides a larger predosing window within which $R_{\mathrm{SH}}$ values remain high, which could be beneficial for run-torun reproducibility of the electrical performance of the asgrown HEMTs. On the other hand, shorter optimization window seems inherent to the TMAl predose, as for similar reaction kinetics $\left(\sim 0.3 \mu \mathrm{mol} / \mathrm{s}\right.$ at $\left.980{ }^{\circ} \mathrm{C}\right)$, changes of TMAl flow duration from just 6 to $24 \mathrm{~s}$ have been reported ${ }^{29}$ to increase the diffused aluminum density from $\sim 10^{12}$ to $\sim 10^{15}$ $\mathrm{cm}^{-2}$.

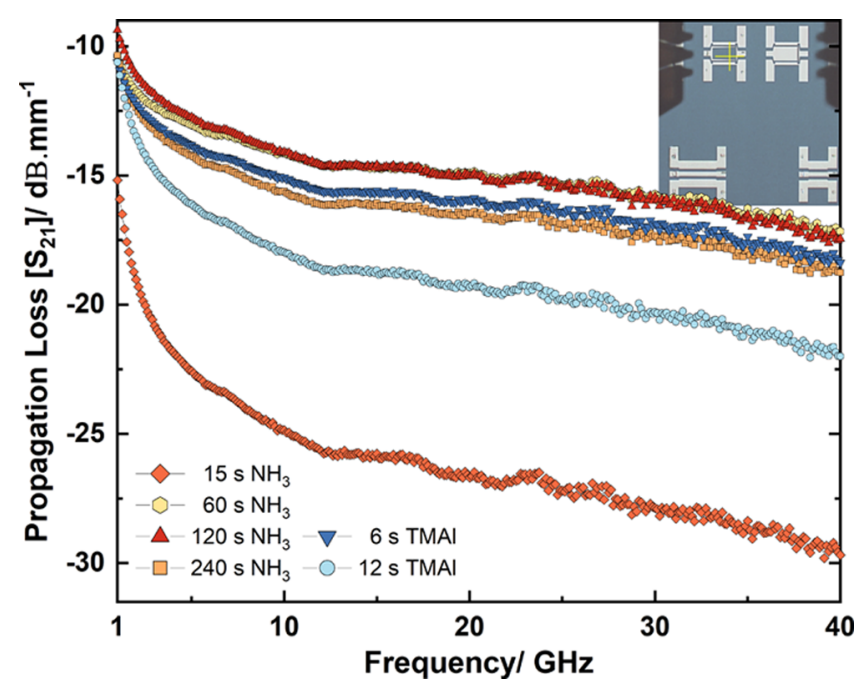

Figure 5. Measured small-signal propagation loss as a function of frequency for ground-signal-ground CPW lines fabricated on the AlN grown with either TMAl or $\mathrm{NH}_{3}$ predose. The data confirms a correlation between the high-frequency loss and previously measured epistructure sheet conductance. A $1 \times 1 \mathrm{~mm}^{2}$ optical micrograph of the fabricated transmission lines and on-chip calibration structure are shown in the inset.

As an indicative measure of the adverse influence of these unintentional conductivities on the high-frequency performance, transmission losses were evaluated from the scattering parameters of coplanar waveguides (CPWs) fabricated on the AlN surfaces (plotted in Figure 5). As shown, for all of the frequencies, the losses were similarly low for the structures with higher sheet-resistance values $\left(60,120\right.$, and $240 \mathrm{~s} \mathrm{NH}_{3}$ predoses and $6 \mathrm{~s}$ TMAl predose) but were considerably higher for both $12 \mathrm{~s}$ TMAl and $15 \mathrm{~s} \mathrm{NH}_{3}$ predoses. In fact, at $40 \mathrm{GHz}$, more than half of the signal power $(-3 \mathrm{~dB})$ was attenuated for the latter.

Radiation losses being negligible in the probed frequency range, ${ }^{34}$ attenuations during signal propagation on such metaldielectric waveguides primarily originate from the nonideality of the materials in the form of dielectric loss and conductor loss. The latter is known to be the dominant factor at $<1 \mathrm{GHz}$ and is controlled by surface resistivity and line inductivity, which should be similar for all of the identically deposited metallic lines. Effectively, this indicates that the sample-tosample variation in measured loss is due to the varying contribution of dielectric loss. It is also known that for a dielectric (AlN-Si composite in this case), the losses ${ }^{34,52}$ are dependent on the dielectric conductivity in the form of effective loss tangent $\left(\tan \delta_{\mathrm{d} \text { eff }}\right)$ as

$$
\tan \delta_{\text {d_eff }}=\tan \delta_{\mathrm{d}}+(\sigma / 2 \pi \varepsilon f)
$$

where the first term represents the dielectric damping, and the second represents the dielectric conduction with $\sigma, \varepsilon$, and $f$ being the conductivity, permittivity, and frequency, respectively. Thus, as the dielectric loss at any particular frequency is directly dependent on the conductivity, the observed variation in signal attenuation among the present structures further accentuates the role of predose in minimizing the losses for GaN-on-Si HEMTs. Also, as listed in Table 3, the losses increase with increase in frequency. Based on the spatial extents of the conductive layers, it is plausible that at lower frequencies the effect of the p-type layer is dominant, and at 
Table 3. Comparison of Propagation Losses (in $\mathrm{dB} / \mathrm{mm}$ ) at Specific Frequencies for $100 \mu \mathrm{m}$ Long CPW Transmission Lines Fabricated on AlN-on-Si Structures Grown with Different Predoses

\begin{tabular}{|c|c|c|c|c|c|c|}
\hline & $\mathrm{NH}_{3} / 15 \mathrm{~s}$ & $\mathrm{NH}_{3} / 60 \mathrm{~s}$ & $\mathrm{NH}_{3} / 120 \mathrm{~s}$ & $\mathrm{NH}_{3} / 240 \mathrm{~s}$ & $\mathrm{TMAl} / 6 \mathrm{~s}$ & $\mathrm{TMAl} / 12 \mathrm{~s}$ \\
\hline loss at $5 \mathrm{GHz}$ & 22.6 & 13.1 & 12.7 & 14.2 & 13.8 & 16.1 \\
\hline loss at $10 \mathrm{GHz}$ & 24.9 & 14.1 & 14.1 & 15.7 & 15.1 & 18.0 \\
\hline loss at $50 \mathrm{GHz}$ & 30.1 & 17.5 & 17.9 & 19.0 & 18.7 & 22.4 \\
\hline
\end{tabular}
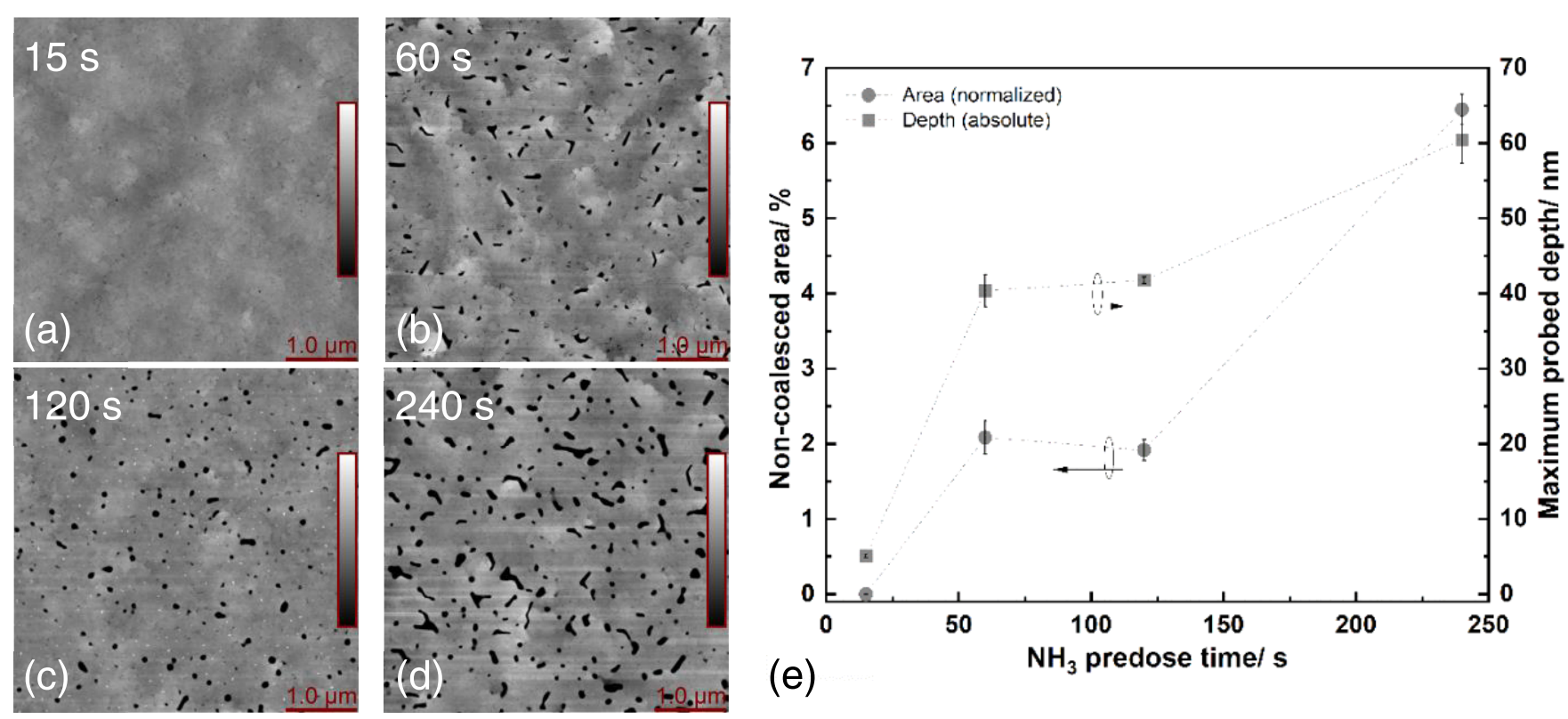

Figure 6. AFM surface topography of $250 \mathrm{~nm}$ AlN epilayers grown with $\mathrm{NH}_{3}$ predose durations of (a) $15 \mathrm{~s}$, (b) $60 \mathrm{~s}$, (c) $120 \mathrm{~s}$, and (d) $240 \mathrm{~s}$ indicates a continuous decrease in coalescence with increase in duration. In all of the scans, the height scales represent $10 \mathrm{~nm}$. The normalized noncoalesced area and the maximum probed depth for each predose are quantified in (e) averaged from three $5 \times 5 \mu \mathrm{m}^{2}$ scans on each wafer.

higher frequencies, capacitive coupling superimposes the effect of the bulk electrons. It must be emphasized that dielectric losses on thick epilayers are proportionate to the losses on corresponding AlN-on-Si templates ${ }^{31}$ as high-frequency signals penetrate deep into the substrate. Thus, the observed predose dependence is expected to persist for fabricated devices that would be several microns away from the AlN/Si interface.

To elucidate the mechanisms behind the effects of the prenucleation growth stages on the interfacial carrier formation, we have further investigated the microstructures of the various samples. First, the as-grown AlN surfaces were scanned by AFM in tapping mode. Representative $5 \times 5 \mu \mathrm{m}^{2}$ images for different $\mathrm{NH}_{3}$ predoses are shown in Figure 6a-d and indicate the influence of the 15-240 s predose step on the final AlN surface. The predominantly flat surfaces were found to contain pits whose depths, widths, and density were dependent upon the predose duration. Further magnified scans revealed that the pit openings were aligned with crystallographic directions (see the Supporting Information). As AlN is unlikely to be etched by $\mathrm{H}_{2}$ at the growth temperatures, these pits are suggestive of aligned crystallites in the process of coalescing with one another. As a measure of this coalescence process, two parameters, namely, the fractional surface area of pits and their maximum depths, were evaluated for each wafer. Understandably, a more coalesced layer should possess a reduced value for both entities. The corresponding trends in Figure 6e demonstrate that as the predose duration increased from 15 to $240 \mathrm{~s}$, the morphology changed from complete merger of the crystallites to $\sim 7 \%$ noncoalesced area. In parallel, the maximum probed pit depth also increased by an order of magnitude though as the size of the individual pits gets smaller, depths are likely to be underestimated due to the AFM tips' inability to access the bottom of high-aspect-ratio holes. The topographies for the TMAl predoses largely resembled that of the $15 \mathrm{~s} \mathrm{NH}_{3}$ predose (see the Supporting Information). Notably, regardless of the predose type/duration before AlN nucleation, the final surface topography after growth of subsequent layers of the complete HEMT structure was always identical and completely coalesced (see the Supporting Information). However, as the CPW lines were directly fabricated on top of the AlN surfaces, the presence of larger voids for longer $\mathrm{NH}_{3}$ predoses may have caused additional scattering of the propagating RF signal. This may explain the slightly higher losses for $240 \mathrm{~s}$ compared to those for 60 and $120 \mathrm{~s} \mathrm{NH}_{3}$ predosed structures at all frequencies, as shown in Figure 5.

Further investigation of the microstructure used crosssectional STEM-EELS investigations of the AlN/Si interface. For this experiment, lamellae from two different HEMT structures having 60 and $240 \mathrm{~s} \mathrm{NH}_{3}$ predosed AlN were prepared for cross-sectional viewing in STEM mode. As depicted in the low-magnification, high-angle annular darkfield (HAADF) image of the $60 \mathrm{~s}$ predosed structure (Figure $7 \mathrm{a})$, the presence of a dark interlayer between the AlN and the $\mathrm{Si}$ was prominent in both the specimens. The absence of channeling in the region suggests disorder and/or intermixing. To chemically identify this interlayer, EELS spectra were acquired from the interfaces, and the high-loss energy range between 70 and $130 \mathrm{eV}$ was scrutinized to probe the different bonding states of $\mathrm{Si}$ and $\mathrm{Al}$ atoms. It was seen that the $\mathrm{Si}-\mathrm{L}_{23}$ 

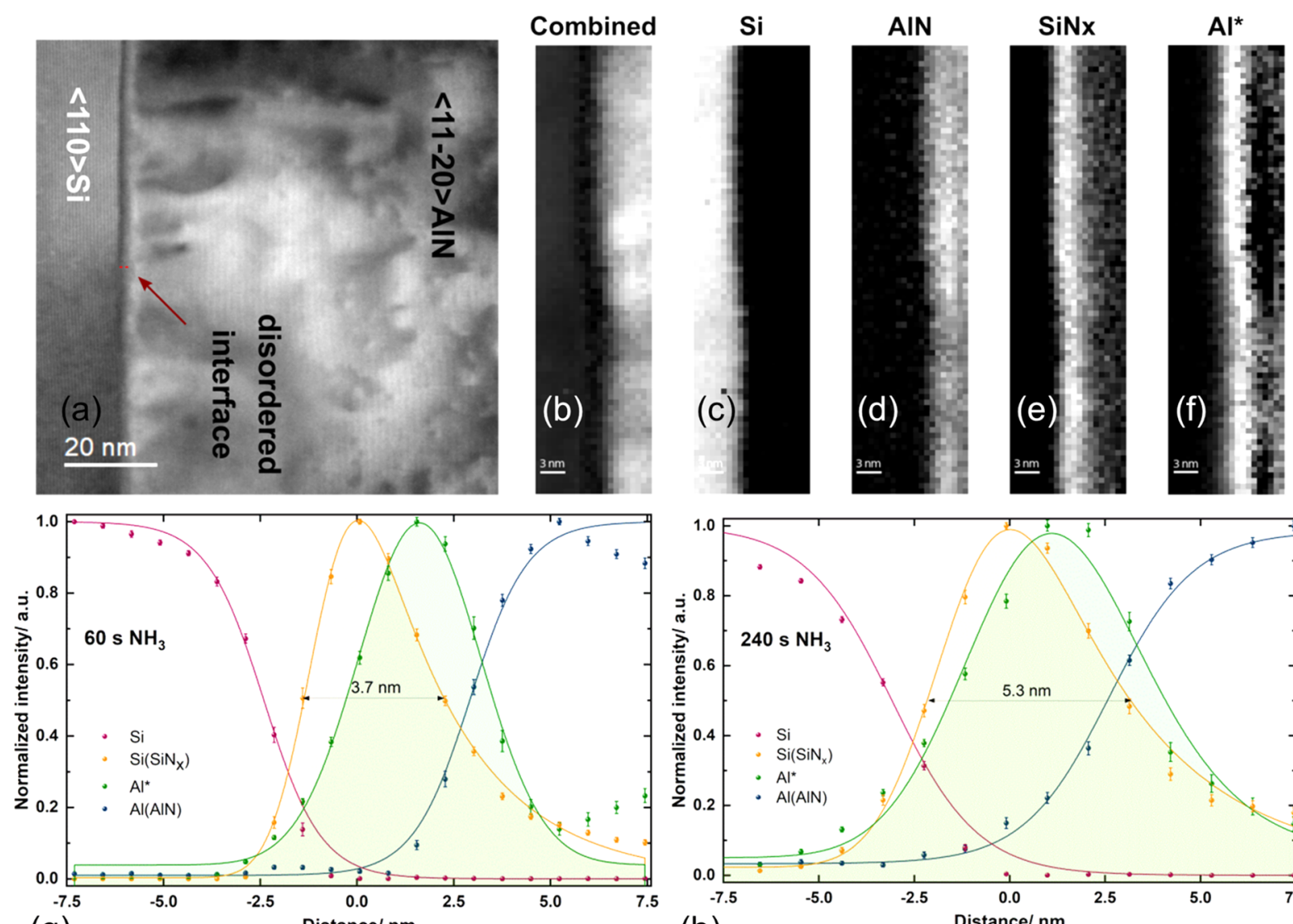

(g)

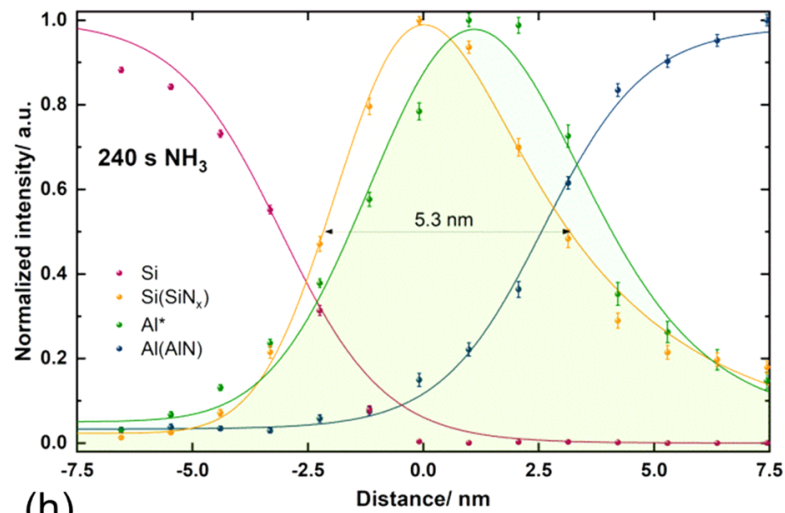

(h)

Figure 7. (a) HAADF-STEM micrograph of the $60 \mathrm{~s} \mathrm{NH}_{3}$ predosed structure showing the presence of a disordered region at the AlN/Si interface. (b) EELS integrated intensity map from a representative $(21 \times 81)$ pixel image of the same interface. The individual chemical profiles were extracted from this EELS signal, and the respective extents are shown in (c) - (f) as intensity maps. The horizontal scale bars in (b) -(f) represent 3 $\mathrm{nm}$. From such multipixel images, averaged intensity profiles of different $\mathrm{Si}$ and $\mathrm{Al}$ states across the interface are plotted in $(\mathrm{g})$ and $(\mathrm{h})$ for 60 and $240 \mathrm{~s} \mathrm{NH}_{3}$ predoses, respectively (all of the profiles are normalized to their individual maximum intensity value, and error bars represent standard errors of the measurement). In both the plots, the zero of the $x$-axis corresponds to the peak of the fitted $\operatorname{Si}\left(\operatorname{SiN}_{x}\right)$ profile, and the calculated full width at half-maxima (FWHMs) of the same are marked. Note the heterogeneity of the $\mathrm{Si}\left(\mathrm{SiN}_{x}\right) / \mathrm{Al}(\mathrm{AlN})$ interface.

edge near the interface had an energy shift compared to Sibulk, owing to charge redistribution ${ }^{46}$ from Si bonded to $\mathrm{Si}$ and $\mathrm{Si}$ bonded to nitrogen in $\mathrm{SiN}_{x}$. In addition, the spectra revealed that near the interface (see the Supporting Information), $\mathrm{Al}-\mathrm{L}_{23}$ edge had shifted from the expected position of $\mathrm{Al}$ in $\mathrm{AlN}$ or $\mathrm{Al}$ to an intermediate bonding state, which does not correspond to a known reference compound, which we have termed as $\mathrm{Al}^{*}$. The $2 \mathrm{D}$ EELS intensity map around the AlN/Si interface of the $60 \mathrm{~s} \mathrm{NH}_{3}$ predosed sample is shown in Figure $7 b$. In Figure $7 c-f$, separate maps of the different signals at this interface are given, which show the following features:

1. Si signal corresponding to elemental $\mathrm{Si}$ is seen to the left of Figure $7 c$, specifying the position of the silicon substrate.

2. Al signal corresponding to AlN is seen to the right of Figure $7 \mathrm{~d}$, specifying the position of the AlN layer.

3. Si signal corresponding to $\mathrm{SiN}_{x}$ is seen as a band in the center of Figure $7 \mathrm{e}$, positioned between the silicon substrate and the AlN layer.

4. $\mathrm{Al}^{*}$ signal is seen as a band in the center of Figure $7 \mathrm{f}$, also positioned between the silicon substrate and the AlN layer.
To quantify the spatial extent of these different bonding states, the extracted spectra for each species were then averaged as a function of width along the interface. The resulting chemical profiles, integrated across the interface, are plotted for 60 and $240 \mathrm{~s} \mathrm{NH}_{3}$ predoses in Figure $7 \mathrm{~g}$, h, respectively. From the extracted intensities, the fitted widths for the $\operatorname{Si}\left(\operatorname{SiN}_{x}\right)$ profile reveal FWHMs of $3.7 \pm 0.2$ and $5.3 \pm$ $0.2 \mathrm{~nm}$ for 60 and $240 \mathrm{~s}$ of $\mathrm{NH}_{3}$ predose, respectively. In addition, comparable width and significant spatial overlap of the $\mathrm{Al}^{*}$ profile in both the instances suggest that instead of binary $\operatorname{SiN}_{x}$ that has been suggested till date, ${ }^{30,43,46,53,54}$ an intermixed $\mathrm{AlSiN}$ alloy exists at the $\mathrm{AlN} / \mathrm{Si}$ interface. The thicknesses further confirm that for $\mathrm{NH}_{3}$ predoses, a higher duration leads to a thicker layer between the Si substrate and the low-temperature AlN nucleation layer. A detailed spectroscopic analysis on this interlayer will be published separately.

II.III. Origins of the Carriers and the Role of the Predose. Given the electrical and structural characteristics of the wafers, it is evident that the overall conductivity comprises distinct origins. To begin with, the drastic fall in sheet resistance of the annealed substrate along with the uniform concentration of electrons throughout the bulk indicates the formation of thermally generated donors during the heating of the Si wafer. Hence, the high resistivity of the substrate is not 
impervious to high temperatures in a $\mathrm{H}_{2}$ ambient, and even the 30 min long oxide desorption step at $1080{ }^{\circ} \mathrm{C}$ is sufficient to significantly reduce the initial resistivity of the HR-Si. The implication of the thermal cycling on the conductivity of $\mathrm{Si}$ wafers has not been widely recognized in the III-nitride growth literature despite the reduction of resistivity and reversal in majority carrier type as a result of thermal annealing being understood since the earliest Si microwave ICs. ${ }^{55}$ The source of this bulk conductivity is likely associated with the generation of one or multiple thermally induced donors. ${ }^{56-58}$ Oxygen precipitates are plausible candidates considering the high levels of intrinsic oxygen present in CZ-grown Si. Passivation of residual substrate impurities by hydrogen ${ }^{38}$ during the hightemperature annealing step cannot be ruled out either. Further work understanding the role of the thermal profile of the $\mathrm{Si}$ during the growth of III-nitride heterostructures may allow control or at least reduction of their concentration. This would not only decrease the overall conductance of the n-type layer but also increase the $\mathrm{p}-\mathrm{n}$ junction depletion width, which, owing to the difference in $\mathrm{p}$ - and $\mathrm{n}$-carrier concentrations, primarily penetrates into the n-region. Effectively, this would reduce the capacitive coupling of devices to these electrons and could complement processing-based approaches of thinning or local substrate removal ${ }^{28,59}$ to provide a viable option to circumvent this bottleneck. It is worth mentioning that additional diffusion of susceptor contaminants through the backside of the silicon at high temperatures may have contributed to the measured sheet resistance of the wafers with full thickness. This is derived from the fact that only for the generated bulk electrons, the $R_{\mathrm{SH}}$ of the annealed substrate, i.e., RS-2 with $1000 \mu \mathrm{m}$ thickness, should have been approximately $840 \Omega / \square$ instead of the much lower 596 $\Omega / \square$ that was measured. While this backside conductivity far away from the device plane is not considered to be important for the operation of GaN-on-Si HEMTs and can be removed by simple backside grinding, it clearly contributes to the eddy current measurement and must be considered for wafer level measurements.

In view of other possible sources, the interfacial AlSiN is a disordered alloy and is expected to have low mobility and, hence, is unlikely to contribute to the high-frequency conductance. However, in comparison to the distributed ntype layer evidenced above, the p-type layer at the AlN/Si interface has significantly higher conductivity and would also have closer capacitive coupling with the 2DEG channel in a HEMT. It is emphasized that though all of the AlN layers were thicker than the proposed limiting thickness ${ }^{24}$ for inversion electrons, any evidence of interfacial electrons was absent. As for the holes, the agreement of the SCM-observed distribution of the p-type region with the reported SIMS depth profiles of $\mathrm{Al}$ reported in the literature confirms that the holes are indeed of extrinsic origin arising from group-III elemental in-diffusion. The SIMS depth profile of RS-2 further proves that this diffusion does not occur prior to the injection of organometallics into the reactor. Hence, for the $\mathrm{NH}_{3}$ predosed AlNon-Si templates, diffusion must have occurred during the nucleation period that ends once the silicon is covered with AlN and/or during the rest of the bulk AlN growth. It is noted that $\mathrm{SiN}_{x}$ has been proposed to act as a diffusion barrier, ${ }^{27}$ and it has also been suggested ${ }^{9,43}$ that even with an amorphous $\mathrm{SiN}_{x}$, through the interface $\mathrm{Si}-\mathrm{SiN}-\mathrm{AlN}$ crystalline, relationship is maintained by intermittent local zones where the $\mathrm{SiN}_{x}$ is discontinuous. In this context, higher $\mathrm{NH}_{3}$ predoses are expected to result in thicker interlayers (as observed) and provide more coverage of the exposed silicon, both plausibly prohibiting direct diffusion of $\mathrm{Al}$ during the nucleation phase. If significant diffusion during the bulk growth period takes place instead, defects such as grain boundaries and dislocations are expected to facilitate the process. Increasing the $\mathrm{NH}_{3}$ predose duration has been reported r3-45 $^{40}$ yield lower dislocation density in GaN buffer, and a commensurate density reduction in the AlN nucleation layer ${ }^{45}$ itself has been suggested as the underlying cause. Based on the observed delay in coalescence with increase in the predose duration, we anticipate that thicker $\mathrm{SiN}_{x}$ functions as more efficient local masks ${ }^{60,61}$ to reduce the dislocation densities. Theoretically ${ }^{62}$ and experimentally, ${ }^{63,64}$ dislocations have been proposed to act as diffusion pathways in III-nitrides. Though the diffusivity of $\mathrm{Al}$ through dislocations in $\mathrm{AlN}$ and its dependence on the core structure is yet to be reported, as longer $\mathrm{NH}_{3}$ predoses likely reduce the dislocation density, those may have reduced dislocation-mediated diffusion during the subsequent bulk growth period as well. On the other hand, increasing the $\mathrm{NH}_{3}$ predose duration definitely increases the density of pits, but the anticorrelation between the pitted area and $R_{\mathrm{SH}}$ proves that pit defects are not major contributors to the diffusion process.

In contrast to the $\mathrm{NH}_{3}$ predose, growths using TMAl predose provide an opportunity for direct "Al" diffusion during the predose period itself. Thus, for fixed flow rates, increasing the TMAl predose duration could enhance the density of the group-III species in the substrate by enabling diffusion before nucleation. A progressive increase of the amount of $\mathrm{Al}$ in the substrate with longer ${ }^{29}$ TMAl predoses supports such a mechanism and may explain the relationship between TMAl predose duration and extracted $R_{\mathrm{SH}}$ for the present structures. However, for the short TMAl predose (6 s), the high sheet resistance of the p-type layer confirms that the diffusion during the nucleation and the bulk growth can indeed be restricted to the amounts comparable to the optimized $\mathrm{NH}_{3}$ predoses. Notably, TMAl predosed AlN have also been consistently shown ${ }^{30,46,53,54}$ to include a prominent $\mathrm{SiN}_{x}$ layer forming either from the background " $\mathrm{N}$ " sources or during the first growth phase when both "Al" and " $\mathrm{N}$ " are simultaneously present on exposed silicon. For TMAl predosed structures, evaluation of the interface, morphology, and sheet-resistance/ diffused $\mathrm{Al}$ density at different stages of growth can further reveal the role of $\mathrm{SiN}_{x}$ in post-predose diffusions. Understanding of the diffusion pathways that are active during the latter stages of AlN-on-Si growth is important as they explain the observations ${ }^{24,31}$ of higher RF losses suffered by thicker AlN layers (i.e., longer growth/diffusion times) grown at the same temperature (i.e., same activation energy), independently of the "inversion channel" theory.

\section{CONCLUSIONS}

Systematic electrical and material characterizations have established that the origin of parasitic substrate conduction in MOVPE-grown GaN HEMT heterostructures on HR silicon stems from separate growth-related sources. A substantial reduction in the resistivity of the Czochralski-type silicon substrate just after the high-temperature native oxide desorption step was revealed, and bulk electrons originating from thermally generated donors were attributed as the source of this conduction. In addition, the debated conductive layer at the AlN/Si interface was confirmed to be p-type and most likely originating from group-III acceptors, which had diffused 
several microns into the substrate. It was observed that for particular durations, initiating the growth with either the hydride (i.e., $\mathrm{NH}_{3}$ ) or the organometallic precursor (i.e., TMAl) predose resulted in similar high sheet resistance $(\sim 2000 \Omega / \square)$ of this p-type layer. It is possible that elemental diffusion occurs before, during, or postnucleation of the AlN layer and the efficacy of different predoses is associated with inhibiting the diffusion at different stages of the growth. Also, though the high-frequency signal attenuation was seen to be related to the epistructure sheet resistances, simulations of electromagnetic energy propagation through such lossy dielectrics are needed to distinguish the contribution of the distributed n-type and the localized p-type layer. To date, the high-temperature performance of GaN HEMT on HR-Si has been simulated ${ }^{65}$ based upon the assumption that the intrinsic resistivity of the substrate stays intact even after growth. Based on present findings, it is anticipated that such guidelines will necessitate a re-evaluation. Also, FZ Si intrinsically has lower oxygen levels and may provide better immunity against the thermal generation of bulk donors. However, they would not prevent the unintentional group-III doping close to the AlN/Si interface, which can only be controlled by the predose. In parallel, device architectures, ${ }^{66,67}$ which are less prone to substrate conductivity, may see increasing adaptations. Notably, additional conductivity was also suspected at the back face of the silicon substrates, although this is sufficiently separated from the active device layers that it will not have an impact on device performance.

\section{MATERIALS AND METHODS}

IV.I. Metal-Organic Vapor Phase Epitaxy (MOVPE) Growth. All of the epilayers investigated in this study were grown in an Aixtron $1 \times 6$ MOVPE reactor with a close-coupled showerhead (CCS) geometry. The growth temperatures and temperature uniformities were controlled by in situ calibrated pyrometers of an EpiTT module (emissivity-corrected) and an Argus photodiode array module, respectively. During growth, the thicknesses and surface morphologies were monitored in real time by interferometry at three different wavelengths $(405,633$, and $950 \mathrm{~nm})$. Electronic-grade $(7 \mathrm{~N})$ trimethylaluminum (TMAl, Dow Chemicals), trimethylgallium (TMGa, SAFC), and ammonia $\left(\mathrm{NH}_{3}, \mathrm{BOC}\right)$ were used as the precursor for $\mathrm{Al}, \mathrm{Ga}$, and $\mathrm{N}$, respectively. Pd-cell-purified hydrogen $\left(\mathrm{H}_{2}\right.$, Air Products) with a dew point of $-120^{\circ} \mathrm{C}$ (moisture level $<50$ $\mathrm{ppb}$ ) was used as the carrier gas. The $1 \mathrm{~mm}$ thick 6 in. Czochralski silicon wafers (supplied by Shin-Etsu Handotai) used for the growths had a specified resistivity of $3-10 \mathrm{k} \Omega \mathrm{cm}$. Each growth experiment was followed by manual scraping and brushing of the showerhead to remove deposits from previous depositions and a high-temperature bake. The reactor was continuously purged with nitrogen between runs/bakes.

IV.II. Eddy Current-Based Noninvasive Sheet-Resistance Measurement. The $R_{S H}$ of intact 6 in. wafers were measured in an LEI 1510 instrument that induces eddy currents in the semiconductor by oscillating magnetic fields that are coupled through an RF tank circuit. The power absorbed in the material is converted to conductance with reference to calibrated standards. The probed area for each measurement was $\sim 1.5 \mathrm{~cm}^{2}$, and 51 separate positions were measured for each wafer.

IV.III. Secondary Ion Mass Spectroscopy (SIMS). SIMS depth profile in the silicon was measured by EAG Laboratories, either with $\mathrm{Cs}^{+}$primary beam (to detect $\mathrm{H}, \mathrm{C}, \mathrm{N}$, and $\mathrm{O}$ as negative ions) or with $\mathrm{O}_{2}{ }^{+}$primary beam (to detect $\mathrm{B}, \mathrm{Al}$, and $\mathrm{Ga}$ as positive ions) having beam energies $1-30 \mathrm{keV}$. The top surface of a scribed specimen from the oxide-desorbed silicon substrate (RS-2) was subjected to the analysis.
IV.IV. Hall-Effect Measurement. First $1 \times 1 \mathrm{~cm}^{2}$ square specimens were scribed from each wafer, and indium contacts were soldered $\left(300{ }^{\circ} \mathrm{C}\right.$ for $\left.60 \mathrm{~s}\right)$ at the four corners to realize the van der Pauw (vdP) geometry. For the $800 \mu \mathrm{m}$ thick AlN-on-Si specimens, only the contacts on the backside silicon were found to be ohmic. These contacts were used for four-probe Hall-effect measurements in an Ecopia HMS 5500 system with $560 \mathrm{mT}$ magnets. After complete removal of AlN by polishing, ohmic behavior could be realized with topside contacts as well. For the untreated silicon wafer (RS-1), I-V curves could not be acquired due to the excessively high potential drop even at the system limit of $5 \mathrm{nA}$ current, attesting the highly resistive nature of the pristine substrates.

IV.V. Atomic Force Microscopy (AFM) and Scanning Capacitance Microscopy (SCM). As-grown AlN surface topographies were assessed in a Bruker Dimension Icon AFM system with SiN tips (Scanasyst-Air tips by Bruker, spring constant $=0.4 \mathrm{~N}$ / $\mathrm{m})$. Topographic data were acquired in the peakforce tapping mode and analyzed with Nanoscope Analysis 1.9 and Image ${ }^{68}$ software. For morphological quantification in Figure 6e, the $512 \times 512$ pixels in every image were categorized based on their depth and those below a certain value (threshold height, -ve) were considered to be part of a pit. This way, shallow pits related to dislocations were excluded from the analysis. The total areas occupied by the deeper pixels were then normalized against the imaged areas and are presented as a measure of noncoalescence. The maximum depth among all pixels in each image was considered as the maximum probe depth.

SCM scans were carried out on the cross section of specimens cleaved from the AlN-on-Si templates. Preparing vertically abrupt sidewalls for examination, however, proved to be impossible owing to the (111) orientation of the substrate. Among all of the types, the sidewalls perpendicular to the $\langle 110\rangle$ wafer notch were found to have the least surface tear and were chosen for the scans. As-cleaved samples were first blown with purified $\mathrm{N}_{2}$ and then heated on a hot plate at $250{ }^{\circ} \mathrm{C}$ for $20 \mathrm{~min}$ (ensuring minimal surface states in the native oxide). After soldering a large indium ohmic contact on the $\mathrm{Si}$ side, the specimens were mounted on a dedicated fixture with the Si side electrically contacting the metallic chuck. The AFM was equipped with an SCM module for the measurements. The used PtIr-coated doped Si tips (SCM-PIC-V2 from Bruker, spring const. = $0.1 \mathrm{~N} / \mathrm{m}$ ) had a specified tip-radius of $25 \mathrm{~nm}$, which is slightly more than the distance between the acquired pixels (512 pixels in $10 \mu \mathrm{m}$ ). Thus, the spatial resolution is expected to be limited by the distribution of the depletion region under the tip. In the electrical configuration, the tip was kept grounded and all of the biases were applied to the specimen through the chuck. The frequency of the 0.5 VAC input signal was kept fixed at $90 \mathrm{kHz}$ to allow only the majority carriers to respond. Corresponding differential capacitance was sensed as the change in the voltage output of a connected high- $Q$ resonant circuit $\left(f_{0} \sim 1 \mathrm{GHz}\right)$. For each specimen, the lock-in phase $\left(\phi_{\mathrm{L}}\right)$ was optimized to offset the stray capacitances and to maximize the SNR. Unless specified, no DC bias was applied. After the acquisition, the data were analyzed with Nanoscope Analysis 1.9 and Gwyddion ${ }^{69}$ software.

IV.VI. Coplanar Waveguide (CPW) Fabrication and Transmission Loss Measurement. Conventional photolithography technique was used to fabricate identical $50 \Omega \mathrm{CPW}$ transmission lines $^{65}$ on top of the AlN-on-Si templates. All of the samples were identically processed in the same batch, but the metal layers were not optimized, which may have affected the absolute magnitudes of the cumulative losses. Small-signal s-parameters of the CPW lines were measured with ground-signal-ground probes while mounted on a Cascade Summit 12000M station. Short-open-load-thru (SOLT) calibration was performed before measurements using an off-wafer impedance-standard-substrate (ISS). A Rhode and Schwarz ZVA-67 vector network analyzer (VNA) was used for both calibration and measurements.

IV.VII. Scanning Transmission Electron Microscopy (STEM) and Electron Energy Loss Spectroscopy (EELS). Transmission electron microscopy (TEM) lamellae $(\sim 50 \mathrm{~nm}$ thin) were prepared via focus ion beam milling using an FEI Helios equipped with a Ga 
ion beam. STEM imaging in conventional dark-field (DF) and highangle annular dark-field (HAADF) modes were carried out in an FEI Tecnai Osiris microscope equipped with a high-brightness XFEG source and operated at $200 \mathrm{kV}$ and an $80 \mathrm{pA}$ beam current. EELS was performed with Gatan's Enfinium ER 977 (energy resolution $~ 0.65$ $\mathrm{eV}$ ) as the spectrometer in dual EELS mode measuring the zero-loss peak and the low loss in the range of $45-255 \mathrm{eV}$. All of the EELS micrographs were acquired with an electron beam convergence angle of $11 \mathrm{mrad}$, an acceptance angle of $25 \mathrm{mrad}$, and a dwell time of $1 \mathrm{~s} /$ pixel with subpixel rastering.

\section{ASSOCIATED CONTENT}

\section{(s) Supporting Information}

The Supporting Information is available free of charge at https://pubs.acs.org/doi/10.1021/acsaelm.0c00966.

Cross-sectional SCM with DC bias, AFM of the surface pits on the $\mathrm{NH}_{3}$ predosed templates, AFM of the topography of TMAl predosed templates and generic $\mathrm{NH}_{3}$ predosed HEMT structure, and EELS spectra at different positions of the interface (PDF)

\section{AUTHOR INFORMATION}

\section{Corresponding Author}

Saptarsi Ghosh - Department of Materials Science and Metallurgy, University of Cambridge, Cambridge CB3 OFS, United Kingdom; (1) orcid.org/0000-0003-1685-6228; Email: saptarsi.ghosh@ieee.org

\section{Authors}

Alexander Hinz - Department of Materials Science and Metallurgy, University of Cambridge, Cambridge CB3 OFS, United Kingdom; (1) orcid.org/0000-0002-8845-0086

Simon M. Fairclough - Department of Materials Science and Metallurgy, University of Cambridge, Cambridge CB3 OFS, United Kingdom

Bogdan F. Spiridon - Department of Materials Science and Metallurgy, University of Cambridge, Cambridge CB3 OFS, United Kingdom

Abdalla Eblabla - Centre for High Frequency Engineering, University of Cardiff, Cardiff CF24 3AA, United Kingdom

Michael A. Casbon - Centre for High Frequency Engineering, University of Cardiff, Cardiff CF24 3AA, United Kingdom

Menno J. Kappers - Department of Materials Science and Metallurgy, University of Cambridge, Cambridge CB3 OFS, United Kingdom

Khaled Elgaid - Centre for High Frequency Engineering, University of Cardiff, Cardiff CF24 3AA, United Kingdom

Saiful Alam - Centre for High Frequency Engineering, University of Cardiff, Cardiff CF24 3AA, United Kingdom

Rachel A. Oliver - Department of Materials Science and Metallurgy, University of Cambridge, Cambridge CB3 OFS, United Kingdom; (1) orcid.org/0000-0003-0029-3993

David J. Wallis - Department of Materials Science and Metallurgy, University of Cambridge, Cambridge CB3 OFS, United Kingdom; Centre for High Frequency Engineering, University of Cardiff, Cardiff CF24 3AA, United Kingdom

Complete contact information is available at:

https://pubs.acs.org/10.1021/acsaelm.0c00966

\section{Notes}

The authors declare no competing financial interest.

\section{ACKNOWLEDGMENTS}

This research was supported by the Engineering and Physical Sciences Research Council (EPSRC) under the grant InGaNET, "Integration of RF Circuits with High Speed GaN Switching on Silicon Substrates" (EP/N017927/1) and (EP/ N014820/2). A.H. acknowledges the Deutsche Forschungsgemeinschaft for his Research Fellowship at the University of Cambridge. D.J.W. acknowledges the support of EPSRC fellowship $(\mathrm{EP} / \mathrm{N} 01202 \mathrm{X} / 2)$. The authors are grateful to Plessey Semiconductors Ltd. for performing the Si wafer backthinning and to Christopher Richards and Robert Harper of Compound Semiconductor Center Ltd. for performing the contactless sheet-resistance mapping. S.G. thanks Jagannath Kuchlyan (Department of Chemistry, University of Oxford) for suggestions on the data analysis.

\section{REFERENCES}

(1) Balmer, R. S.; Hilton, K. P.; Nash, K. J.; Uren, M. J.; Wallis, D. J.; Wells, A.; Missous, M.; Martin, T. AlGaN/GaN Microwave HFET Including a Thin AlN Carrier Exclusion Layer. Phys. Status Solidi C 2003, 2331-2334.

(2) Palacios, T.; Chakraborty, A.; Heikman, S.; Keller, S.; DenBaars, S. P.; Mishra, U. K. AlGaN/GaN High Electron Mobility Transistors with InGaN Back-Barriers. IEEE Electron Device Lett. 2006, 27, 1315

(3) Arulkumaran, S.; Egawa, T.; Ishikawa, H.; Jimbo, T.; Sano, Y. Surface Passivation Effects on AlGaN/GaN High-Electron-Mobility Transistors with SiO2, Si3N4, and Silicon Oxynitride. Appl. Phys. Lett. 2004, 84, 613-615.

(4) Medjdoub, F.; Alomari, M.; Carlin, J.-F.; Gonschorek, M.; Feltin, E.; Py, M. A.; Grandjean, N.; Kohn, E. Barrier-Layer Scaling of InAlN/GaN HEMTs. IEEE Electron Device Lett. 2008, 29, 422-425.

(5) Sanyal, I.; Lee, Y.-C.; Chen, Y.-C.; Chyi, J.-I. Achieving High Electron Mobility in AlInGaN/GaN Heterostructures: The Correlation between Thermodynamic Stability and Electron Transport Properties. Appl. Phys. Lett. 2019, 114, No. 222103.

(6) Krost, A.; Dadgar, A. GaN-Based Optoelectronics on Silicon Substrates. Mater. Sci. Eng., B 2002, 93, 77-84.

(7) Khoury, M.; Tottereau, O.; Feuillet, G.; Vennéguès, P.; ZúñigaPérez, J. Evolution and Prevention of Meltback Etching: Case Study of Semipolar GaN Growth on Patterned Silicon Substrates. J. Appl. Phys. 2017, 122, No. 105108.

(8) Dadgar, A. Sixteen Years GaN on Si. Phys. Status Solidi B 2015, 252, 1063-1068.

(9) Zhu, D.; Wallis, D. J.; Humphreys, C. J. Prospects of III-Nitride Optoelectronics Grown on Si. Rep. Prog. Phys. 2013, 76, No. 106501.

(10) Watanabe, A.; Takeuchi, T.; Hirosawa, K.; Amano, H.; Hiramatsu, K.; Akasaki, I. The Growth of Single Crystalline GaN on a Si Substrate Using AIN as an Intermediate Layer. J. Cryst. Growth 1993, 128, 391-396.

(11) Feng, Y.; Wei, H.; Yang, S.; Chen, Z.; Wang, L.; Kong, S.; Zhao, G.; Liu, X. Competitive Growth Mechanisms of AlN on Si (111) by MOVPE. Sci. Rep. 2015, 4, No. 6416.

(12) Yang, Y.; Xiang, P.; Liu, M.; Chen, W.; He, Z.; Han, X.; Ni, Y.; Yang, F.; Yao, Y.; Wu, Z.; Liu, Y.; Zhang, B. Effect of Compositionally Graded AlGaN Buffer Layer Grown by Different Functions of Trimethylaluminum Flow Rates on the Properties of GaN on $\mathrm{Si}$ (111) Substrates. J. Cryst. Growth 2013, 376, 23-27.

(13) Leung, B.; Han, J.; Sun, Q. Strain Relaxation and Dislocation Reduction in AlGaN Step-Graded Buffer for Crack-Free GaN on Si (111). Phys. Status Solidi C 2014, 11, 437-441.

(14) Ivo, P.; Glowacki, A.; Bahat-Treidel, E.; Lossy, R.; Würfl, J.; Boit, C.; Tränkle, G. Comparative Study of AlGaN/GaN HEMTs Robustness versus Buffer Design Variations by Applying Electroluminescence and Electrical Measurements. Microelectron. Reliab. 2011, 51, 217-223. 
(15) Choi, F. S.; Griffiths, J. T.; Ren, C.; Lee, K. B.; Zaidi, Z. H.; Houston, P. A.; Guiney, I.; Humphreys, C. J.; Oliver, R. A.; Wallis, D. $\mathrm{J}$. Vertical Leakage Mechanism in GaN on Si High Electron Mobility Transistor Buffer Layers. J. Appl. Phys. 2018, 124, No. 055702.

(16) Uren, M. J.; Silvestri, M.; Casar, M.; Hurkx, G. A. M.; Croon, J. A.; Sonsky, J.; Kuball, M. Intentionally Carbon-Doped AlGaN/GaN HEMTs: Necessity for Vertical Leakage Paths. IEEE Electron Device Lett. 2014, 35, 327-329.

(17) Kumar, S.; Gupta, P.; Guiney, I.; Humphreys, C. J.; Raghavan, S.; Muralidharan, R.; Nath, D. N. Temperature and Bias Dependent Trap Capture Cross Section in AlGaN/GaN HEMT on 6-in Silicon With Carbon-Doped Buffer. IEEE Trans. Electron Devices 2017, 64, 4868-4874.

(18) Medjdoub, F.; Zegaoui, M.; Grimbert, B.; Ducatteau, D.; Rolland, N.; Rolland, P. A. First Demonstration of High-Power GaNon-Silicon Transistors at $40 \mathrm{GHz}$. IEEE Electron Device Lett. 2012, 33, $1168-1170$.

(19) Hoshi, S.; Itoh, M.; Marui, T.; Okita, H.; Morino, Y.; Tamai, I.; Toda, F.; Seki, S.; Egawa, T. 12.88 W/Mm GaN High Electron Mobility Transistor on Silicon Substrate for High Voltage Operation. Appl. Phys. Express 2009, 2, No. 061001.

(20) Tirelli, S.; Marti, D.; Haifeng, Sun.; Alt, A. R.; Benedickter, H.; Piner, E. L.; Bolognesi, C. R. 107-GHz (Al,Ga)N/GaN HEMTs on Silicon With Improved Maximum Oscillation Frequencies. IEEE Electron Device Lett. 2010, 31, 296-298.

(21) Bouzid-Driad, S.; Maher, H.; Defrance, N.; Hoel, V.; De Jaeger, J.-C.; Renvoise, M.; Frijlink, P. AlGaN/GaN HEMTs on Silicon Substrate With 206-GHz FMAX. IEEE Electron Device Lett. 2013, 34, $36-38$.

(22) Chung, J. W.; Hoke, W. E.; Chumbes, E. M.; Palacios, T. AlGaN/GaN HEMT With 300-GHz Fmax. IEEE Electron Device Lett. 2010, 31, 195-197.

(23) Fu, X.-C.; Lv, Y.; Zhang, L.-J.; Zhang, T.; Li, X.-J.; Song, X.; Zhang, Z.; Fang, Y.; Feng, Z. High-Frequency InAlN/GaN HFET with f Max over $400 \mathrm{GHz}$. Electron. Lett. 2018, 54, 783-785.

(24) Luong, T. T.; Lumbantoruan, F.; Chen, Y.; Ho, Y.; Weng, Y.; Lin, Y.; Chang, S.; Chang, E. RF Loss Mechanisms in GaN-based High-electron-mobility-transistor on Silicon: Role of an Inversion Channel at the AlN/Si Interface. Phys. Status Solidi A 2017, 214 No. 1600944.

(25) Yacoub, H.; Fahle, D.; Finken, M.; Hahn, H.; Blumberg, C.; Prost, W.; Kalisch, H.; Heuken, M.; Vescan, A. The Effect of the Inversion Channel at the AlN/Si Interface on the Vertical Breakdown Characteristics of GaN-Based Devices. Semicond. Sci. Technol. 2014, 29, No. 115012.

(26) Chandrasekar, H.; Bhat, K. N.; Rangarajan, M.; Raghavan, S.; Bhat, N. Thickness Dependent Parasitic Channel Formation at AlN/ Si Interfaces. Sci. Rep. 2017, 7, No. 15749.

(27) Hanson, A. W.; Roberts, J. C.; Piner, E. L.; Rajagopal, P. IIINitride Material Structures Including Silicon Substrates. US7,247,889B2, 2007.

(28) Pattison, L.; Boles, T.; Tuffy, N.; Lopes, G. In Improving GaN on Si Power Amplifiers through Reduction of Parasitic Conduction Layer, 2014 9th European Microwave Integrated Circuit Conference; IEEE, 2014; pp 92-95.

(29) Matsumoto, K.; Ono, T.; Honda, Y.; Torigoe, K.; Kushimoto, M.; Amano, H. Origin of Acceptor Diffusion into Silicon Substrate during GaN Growth by Metal Organic Chemical Vapor Deposition. Jpn. J. Appl. Phys. 2019, 58, No. 075502.

(30) Chang, S.; Zhao, M.; Spampinato, V.; Franquet, A.; Do, T.-H.; Uedono, A.; Luong, T. T.; Wang, T.-H.; Chang, L. The Influence of AlN Nucleation Layer on Radio Frequency Transmission Loss of AlN-on-Si Heterostructure. Phys. Status Solidi A 2020, 217, No. 1900755.

(31) Chang, S.; Zhao, M.; Spampinato, V.; Franquet, A.; Chang, L. The Influence of AlN Nucleation Layer on RF Transmission Loss of GaN Buffer on High Resistivity Si (111) Substrate. Semicond. Sci. Technol. 2020, 35, No. 035029.
(32) Bah, M.; Valente, D.; Lesecq, M.; Defrance, N.; Garcia Barros, M.; De Jaeger, J.-C.; Frayssinet, E.; Comyn, R.; Ngo, T. H.; Alquier, D.; Cordier, Y. Electrical Activity at the AlN/Si Interface: Identifying the Main Origin of Propagation Losses in GaN-on-Si Devices at Microwave Frequencies. Sci. Rep. 2020, 10, No. 14166.

(33) Wei, L.; Yang, X.; Shen, J.; Liu, D.; Cai, Z.; Ma, C.; He, X.; Tang, J.; Qi, S.; Xu, F.; Wang, X.; Ge, W.; Shen, B. Al Diffusion at AlN/Si Interface and Its Suppression through Substrate Nitridation. Appl. Phys. Lett. 2020, 116, No. 232105.

(34) Berber, F.; Johnson, D. W.; Sundqvist, K. M.; Piner, E. L.; Huff, G. H.; Rusty Harris, H. RF Dielectric Loss Due to MOCVD Aluminum Nitride on High Resistivity Silicon. IEEE Trans. Microwave Theory Tech. 2017, 65, 1465-1470.

(35) Hoke, W. E.; Kennedy, T. D.; Mosca, J. J.; Kerr, A. J.; Torabi, A.; Davis-Hearns, S.; LaRoche, J. R. AlGaN/GaN High Electron Mobility Transistors on $100 \mathrm{Mm}$ Silicon Substrates by Plasma Molecular Beam Epitaxy. J. Vac. Sci. Technol., B: Nanotechnol. Microelectron.: Mater., Process., Meas., Phenom. 2011, 29, No. 03 C107.

(36) Cordier, Y.; Comyn, R.; Frayssinet, E.; Khoury, M.; Lesecq, M.; Defrance, N.; De Jaeger, J.-C. Influence of AlN Growth Temperature on the Electrical Properties of Buffer Layers for GaN HEMTs on Silicon. Phys. Status Solidi A 2018, 215, No. 1700637.

(37) Heinrich, W.; Gerdes, J.; Schmuckle, F. J.; Rheinfelder, C.; Strohm, K. Coplanar Passive Elements on Si Substrate for Frequencies up to $110 \mathrm{GHz}$. IEEE Trans. Microwave Theory Tech. 1998, 46, 709-712.

(38) Härkönen, J.; Tuominen, E.; Tuovinen, E.; Mehtälä, P.; LassilaPerini, K.; Ovchinnikov, V.; Heikkilä, P.; Yli-Koski, M.; Palmu, L.; Kallijärvi, S.; Nikkilä, H.; Anttila, O.; Niinikoski, T.; Eremin, V.; Ivanov, A.; Verbitskaya, E. Processing of Microstrip Detectors on Czochralski Grown High Resistivity Silicon Substrates. Nucl. Instrum. Methods Phys. Res., Sect. A 2003, 514, 173-179.

(39) Dadgar, A.; Weyers, M. Metalorganic Vapor Phase Epitaxy (MOVPE): Growth, Materials Properties, and Applications, 1st ed.; Irvine, S.; Capper, P., Eds.; John Wiley \& Sons Ltd., 2020.

(40) Krupka, J.; Nguyen, D.; Mazierska, J. Microwave and RF Methods of Contactless Mapping of the Sheet Resistance and the Complex Permittivity of Conductive Materials and Semiconductors. Meas. Sci. Technol. 2011, 22, No. 085703.

(41) Waller, W. M.; Karboyan, S.; Uren, M. J.; Lee, K. B.; Houston, P. A.; Wallis, D. J.; Guiney, I.; Humphreys, C. J.; Kuball, M. Interface State Artefact in Long Gate-Length AlGaN/GaN HEMTs. IEEE Trans. Electron Devices 2015, 62, 2464-2469.

(42) Lee, K. B.; Guiney, I.; Jiang, S.; Zaidi, Z. H.; Qian, H.; Wallis, D. J.; Uren, M. J.; Kuball, M.; Humphreys, C. J.; Houston, P. A. Enhancement-Mode Metal-Insulator-Semiconductor GaN/AlInN/ GaN Heterostructure Field-Effect Transistors on Si with a Threshold Voltage of $+3.0 \mathrm{~V}$ and Blocking Voltage above $1000 \mathrm{~V}$. Appl. Phys. Express 2015, 8, No. 036502.

(43) Arslan, E.; Ozturk, M. K.; Duygulu, Ö.; Kaya, A. A.; Ozcelik, S.; Ozbay, E. The Influence of Nitridation Time on the Structural Properties of GaN Grown on Si (111) Substrate. Appl. Phys. A: Mater. Sci. Process. 2009, 94, 73-82.

(44) Rahman, M. N. A.; Yusuf, Y.; Mansor, M.; Shuhaimi, A. Effect of Nitridation Surface Treatment on Silicon ( $\left.\begin{array}{lll}1 & 1 & 1\end{array}\right)$ Substrate for the Growth of High Quality Single-Crystalline GaN Hetero-Epitaxy Layer by MOCVD. Appl. Surf. Sci. 2016, 362, 572-576.

(45) Kadir, A.; Srivastava, S.; Li, Z.; Lee, K. E. K.; Sasangka, W. A.; Gradecak, S.; Chua, S. J.; Fitzgerald, E. A. Influence of Substrate Nitridation on the Threading Dislocation Density of GaN Grown on $200 \mathrm{Mm} \mathrm{Si} \mathrm{(111)} \mathrm{Substrate.} \mathrm{Thin} \mathrm{Solid} \mathrm{Films} \mathrm{2018,} \mathrm{663,} \mathrm{73-78.}$

(46) Radtke, G.; Couillard, M.; Botton, G. A.; Zhu, D.; Humphreys, C. J. Scanning Transmission Electron Microscopy Investigation of the $\mathrm{Si}(111) /$ AlN Interface Grown by Metalorganic Vapor Phase Epitaxy. Appl. Phys. Lett. 2010, 97, No. 251901.

(47) Novák, T.; Kostelník, P.; Konečný, M.; Čechal, J.; Kolíbal, M.; Sikola, T. Temperature Effect on Al Predose and AlN Nucleation Affecting the Buffer Layer Performance for the GaN-on-Si Based High-Voltage Devices. Jpn. J. Appl. Phys. 2019, 58, No. SC1018. 
(48) Newman, R. C. Defects in Silicon. Rep. Prog. Phys. 1982, 45,

$1163-1210$.

(49) Oliver, R. A. Advances in AFM for the Electrical Characterization of Semiconductors. Rep. Prog. Phys. 2008, 71, No. 076501.

(50) Sumner, J.; Oliver, R. A.; Kappers, M. J.; Humphreys, C. J. Scanning Capacitance Microscopy Studies of Unintentional Doping in Epitaxial Lateral Overgrowth GaN. J. Appl. Phys. 2009, 106, No. 104503.

(51) Sze, S. M. Semiconductor Devices: Physics and Technology, 2nd ed.; John Wiley \& Sons, 2003.

(52) Pozar, D. M. Microwave Engineering, 2nd ed.; John Wiley \& Sons, 1998.

(53) Bao, Q.; Luo, J.; Zhao, C. Mechanism of TMAl Pre-Seeding in AlN Epitaxy on Si (111) Substrate. Vacuum 2014, 101, 184-188.

(54) Lee, S.-J.; Jang, S.-H.; Lee, S.-S.; Lee, C.-R. Growth and Characterization of In $0.28 \mathrm{Ga} 0.72 \mathrm{~N} / \mathrm{GaN}$ Multiple-Quantum Wells on $\mathrm{Si}(111)$. J. Cryst. Growth 2003, 249, 65-71.

(55) Battershall, B. W.; Emmons, S. P. Optimization of Diode Structures for Monolithic Integrated Microwave Circuits. IEEE J. Solid-State Circuits 1968, 3, 107-112.

(56) Leskoschek, W.; Feichtinger, H.; Vidrich, G. Thermally Induced Defects in N-Type and p-Type Silicon. Phys. Status Solidi A 1973, 20, 601-610.

(57) Rijks, H. J.; Bloem, J.; Giling, L. J. Heat Treatment of Silicon and the Nature of Thermally Induced Donors. J. Appl. Phys. 1979, 50, 1370-1374.

(58) Gregorkiewicz, T.; van Wezep, D. A.; Bekman, H. H. P. T.; Ammerlaan, C. A. J. EPR Studies of Heat-Treatment Centers in $\mathrm{p}$ -Type Silicon. Phys. Rev. B 1987, 35, 3810-3817.

(59) Herbecq, N.; Roch-Jeune, I.; Rolland, N.; Visalli, D.; Derluyn, J.; Degroote, S.; Germain, M.; Medjdoub, F. 1900 V, 1.6 M $\Omega$ Cm 2 AlN/GaN-on-Si Power Devices Realized by Local Substrate Removal. Appl. Phys. Express 2014, 7, No. 034103.

(60) Lee, Y.-B.; Wang, T.; Liu, Y.-H.; Ao, J.-P.; Izumi, Y.; Lacroix, Y.; Li, H.-D.; Bai, J.; Naoi, Y.; Sakai, S. High-Performance $348 \mathrm{Nm}$ AlGaN/GaN-Based Ultraviolet-Light-Emitting Diode with a SiN Buffer Layer. Jpn. J. Appl. Phys. 2002, 41, 4450-4453.

(61) Kappers, M. J.; Datta, R.; Oliver, R. A.; Rayment, F. D. G.; Vickers, M. E.; Humphreys, C. J. Threading Dislocation Reduction in (0001) GaN Thin Films Using SiNx Interlayers. J. Cryst. Growth 2007, 300, 70-74.

(62) Harafuji, K.; Kawamura, K. Magnesium Diffusion at Dislocation in Wurtzite-Type GaN Crystal. Jpn. J. Appl. Phys. 2005, 44, 64956504.

(63) Pearton, S. J.; Cho, H.; LaRoche, J. R.; Ren, F.; Wilson, R. G.; Lee, J. W. Oxygen Diffusion into SiO2-Capped GaN during Annealing. Appl. Phys. Lett. 1999, 75, 2939-2941.

(64) Massabuau, F. C.-P.; Griffin, P. H.; Springbett, H. P.; Liu, Y.; Kumar, R. V.; Zhu, T.; Oliver, R. A. Dislocations as Channels for the Fabrication of Sub-Surface Porous GaN by Electrochemical Etching. APL Mater. 2020, 8, No. 031115.

(65) Chandrasekar, H.; Uren, M. J.; Casbon, M. A.; Hirshy, H.; Eblabla, A.; Elgaid, K.; Pomeroy, J. W.; Tasker, P. J.; Kuball, M. Quantifying Temperature-Dependent Substrate Loss in GaN-on-Si RF Technology. IEEE Trans. Electron Devices 2019, 66, 1681-1687.

(66) Eblabla, A. M.; Li, X.; Wallis, D. J.; Guiney, I.; Elgaid, K. GaN on Low-Resistivity Silicon THz High-Q Passive Device Technology. IEEE Trans. Terahertz Sci. Technol. 2016, 1-5.

(67) Eblabla, A.; Li, X.; Thayne, I.; Wallis, D. J.; Guiney, I.; Elgaid, K. High Performance GaN High Electron Mobility Transistors on Low Resistivity Silicon for X-Band Applications. IEEE Electron Device Lett. 2015, 36, 899-901.

(68) Schneider, C. A.; Rasband, W. S.; Eliceiri, K. W. NIH Image to ImageJ: 25 Years of Image Analysis. Nat. Methods 2012, 9, 671-675.

(69) Nečas, D.; Klapetek, P. Gwyddion: An Open-Source Software for SPM Data Analysis. Open Phys. 2012, 10, 181-188. 